\title{
Os rumos da utopia brasiliense: observações sobre a representação da capital federal no conto "Brasília" de Clarice Lispector
}

\author{
Dijaci David de Oliveira \\ Doutor em Sociologia. Consultor MEC \\ dijaci@gmail.com
}

\begin{abstract}
Resumo O presente trabalho analisa o conto Brasília da escritora Clarice Lispector, composto em dois momentos: nos tensos anos de 1962 e no auge do "milagre econômico". Publicado postumamente, o conto é emblemático e permitenos acompanhar parte das expectativas da sociedade em relação ao futuro da capital. Realizamos uma decomposição do texto e, simultaneamente, um cotejamento com algumas obras historiográficas e sociológicas para compreender o discurso presente no conto. Assim, percebemos no discurso da autora o pressuposto de que a ausência de "povo" acabou por "facilitar" a tomada do poder pelos militares uma vez que sem povo não haveria reação.
\end{abstract}

Palavras-chave: Brasília; cidade; Clarice Lispector.

Nunca te vi de perto; agora vejo
e sinto e apalpo todo o meu desejo
é que sejas em tudo uma cidade
completa, firme, aberta à humanidade,
e tão naturalmente capital
como o Rio é uma coisa sem igual.

C. D. Andrade, Versiprosa, 1967.

A suntuosa Brasília, a esquálida Ceilândia contemplam-se. Qual delas falará primeiro? Que têm a dizer ou a esconder uma em face da outra? Que mágoas, que ressentimentos prestes a saltar da goela coletiva e não se exprimem? Por que Ceilândia fere o majestoso orgulho da flórea capital?

Por que Brasília resplandece ante a pobreza exposta dos barracos de Ceilândia, filhos de majestade de Brasília? E pensam-se, reuniram-se em silêncio as gêmeas criações do bom brasileiro.

C. D. Andrade. Favelário Nacional In: Corpo, 1984. 
Clarice Lispector é identificada nacionalmente como uma das mais expressivas vozes da literatura brasileira. Nasceu na Ucrânia em dezembro de 1925, porém, dois meses depois sua família se mudou para o Brasil. Ela publicou seu primeiro romance em 1944 (Perto do coração selvagem). Ao longo de sua carreira se destacou com diversos outros trabalhos. Clarice Lispector faleceu em 1977, um dia antes de completar 52 anos. Realizando uma leitura crítica sobre a obra de Clarice Lispector, Campedelli e Abdala Jr. (1981, p. 104). afirmam que:

As produções de Clarice Lispector não deixam de se referir à realidade concreta. É admirável sua consciência técnica, adequando forma e conteúdo. Por exemplo, dissocia as unidades narrativas para mostrar a falta de ligações mais profundas na sociedade. Organiza a narrativa em ritmo lento, para contrastar com o movimento da vida nas grandes cidades. Filtra todos os fatos através de uma consciência que se isola do conjunto - eis aí a solidão do homem moderno.

Nesse trecho os autores sintetizam alguns elementos que buscamos nas leituras sobre o espaço urbano. Certamente nos interessa a compreensão da realidade concreta assim como as relações profundas construídas na sociedade, em especial, nas grandes metrópoles modernas. No entanto, o que leva o homem moderno a se tornar um sujeito solitário?

Algumas das obras de Clarice Lispector foram publicadas postumamente, entre elas temos o livro de crônicas Para não esquecer onde podemos ler a crônica intitulada Brasília. Logo no início do texto podemos ler as seguintes palavras da autora: "Brasília é artificial. Tão artificial como deveria ter sido o mundo quando foi criado" (Lispector, 1999, p. 40). Para os detratores da capital brasileira o trecho acima soa um prato cheio. Entretanto devemos compreender a riqueza do jogo de linguagem da autora. A idéia de artificial soa como algo dissimulado, falso ou fictício. É assim que muitos gostariam de ver Brasília. No entanto a autora destaca que Brasília é tão artificial quanto à própria criação do mundo (na hipotética teoria do criacionismo). Assim, podemos afirmar que Brasília é uma criação, um fruto das mãos meticulosas de um artista, ou criador.

Desde antes de sua construção Brasília tem sido objeto de várias discussões. Ao longo dos seus anos de existência o debate tem ganhado vários contornos indo desde concepções geopolíticas a concepções estéticas. Uma pequena revisão na literatura a respeito da cidade mostra o quanto Brasília tem se mostrado capaz de exercer paixões, admirações e ódios homéricos. Brasília se mostra de todas as maneiras para variados interlocutores e, contrariamente, para outros, Brasília não passa de uma ilusão.

Brasília despertou a atenção do mundo ao trazer na sua concepção a marca da arquitetura moderna
(Lopes, 1996; Duarte da Silva, 1997). Porém sua concepção tem chamado atenção para além da arquitetura e do urbanismo. Sobre ela se deitam os olhos de inúmeros outros intelectuais tais como filósofos, sociólogos, escritores, músicos entre outros (Lopes, 1996). Algumas indagações que poderíamos levantar seriam: qual a razão de Brasília ser objeto de tantos exercícios intelectuais? Ou ainda: por que tais exercícios são em geral realizados de forma veementes, ou seja, carregados ou de paixões ou de ódio? Apesar do esforço intelectual, praticamente inexiste consensos sobre a cidade. Metaforicamente, partimos do pressuposto de que a marca da cidade, contrastando com suas linhas retas, está nas curvas da incerteza de seus traços culturais (que sujeito e que práticas urbanas emergirão deste modelo urbanístico?).

Outro aspecto importante que tem sido destacado nas leituras sobre a cidade está nos contrastes sociais (Gouvêa, 1995; Paviani, 1996; Bursztyn e Araújo, 1997; Bursztyn, 2000). Assim, uma das marcas apontadas da cidade é que ela tem assinalado bem uma distinção entre "dois brasis" - a dos incluídos e o dos excluídos, ou mais apropriadamente, os dos ricos e os dos pobres (Demo, 1998). Esta mesma leitura é a que transparece nos poemas de um dos maiores poetas brasileiros - Carlos Drummond de Andrade. Se em um primeiro momento ele demonstrava seu desejo de que Brasília se tornasse uma cidade "completa" (Andrade, 1967), em um segundo momento - 17 anos depois -, o vemos descrever uma contundente ruptura social que tomou conta do cenário brasileiro. Ele relata esta condição ao percorrer os contrastes da pobreza das favelas com a suntuosidade da capital brasileira (Andrade, 1984). Diante de todas estas percepções, faremos aqui, o exercício de pensarmos Brasília a partir de três matrizes analíticas: a primeira será por meio da idéia do significado da cidade, mais especificamente aquele apontado por Aristóteles em A política; a segunda abordagem será feita por meio do paradigma nacional-desenvolvimentista; por fim, refletiremos sobre Brasília tendo por base os discursos sobre sua dinâmica sociocultural.

\section{Uma leitura singular sobre Brasília}

Na mesma linha de Carlos Drummond de Andrade (1967 e 1984), Clarice Lispector (1999) tomou dois momentos específicos em que debruçou seu olhar sobre a capital para refletir suas considerações. Diferente de Andrade que escreveu dois poemas distintos, Lispector compôs uma crônica, Brasília, porém também ressaltando visivelmente dois momentos: "Estive em Brasília em 1962. Escrevi sobre ela o que foi agora mesmo lido. E agora voltei doze anos depois por dois dias. E escrevi 
também. Aí vai tudo o que vomitei” (Lispector, 1999, p. 44). Em 1962 temos o contexto que antecede o Golpe Militar de 1964, o conturbado período da renúncia do presidente Jânio Quadros e a posse de João Goulart e que foi marcado por tentativas golpistas (Dreifuss, 1981; Aquino et al., 2000; Fausto, 2001). Doze anos depois experiênciamos outro contexto, uma forte repressão do Regime Militar e o efeito dos reflexos do milagre econômico que se esgotara no ano anterior (Gorender, 1987; Miranda, 1999; Fausto, 2001).

A crônica assim constituída acaba por produzir duas visões de Clarice Lispector sobre o ser e o vira-ser de Brasília. Nele são retratados diversos cenários fruto da percepção da autora. Pretendemos aqui, portanto, refletir sobre alguns deles. Assim, abordaremos as imagens da arquitetura, das pessoas, dos espaços de sociabilidade e as imagens do poder. Nossa tese é de que as unidades de significados presentes no texto e que produzem respostas e reflexões sobre Brasília são abordadas por meio de duas óticas: a da estética, que destaca a beleza e a novidade, e da incerteza, que indaga sobre o vir-a-ser da cidade.

\section{Uma primeira digressão: Aristóteles e a idéia de cidade}

Não foram poucos os autores que pensaram e escreveram sobre o significado das cidades. Elas sempre exerceram uma forte atração sobre os indivíduos, em especial, por conta da riqueza e da complexidade cultural nela produzidos - Simmel (1973) diria como o homem se adapta às transformações que ocorrem no ambiente metropolitano. Desde o momento de sua chegada que ele vai sofrendo intensas transformações psíquicas que aguçam as noções de calculabilidade, pontualidade e relacionamentos interpessoais. Muito antes, no entanto, a leitura de Aristóteles apontava para uma outra perspectiva. Nela o homem não perderia sua integridade psíquica. A cidade, assim, é fruto e expressão dos mais altos valores do sujeito. Segundo Aristóteles (1985, p. 13):

Vemos que toda cidade é uma espécie de comunidade, e toda comunidade se forma com vistas a algum bem, pois todas as ações de todos os homens são praticadas com vistas ao que lhes parece um bem; se todas as comunidades visam a algum bem, é evidente que a mais importante de todas elas e que inclui todas as outras tem mais que todas este objetivo e visa ao mais importante de todos os bens; ela se chama cidade é é a comunidade política.
A breve exposição de Aristóteles (1985) em epígrafe nos permite imaginar o quanto a idéia de uma grande aglomeração de pessoas vivendo em um mesmo ambiente possui um forte significado. Para o autor "o mais importante de todos os bens" é a cidade porque ela é a mais elevada forma de comunidade. A idéia de cidade em Aristóteles, no entanto, é a idéia a cidadeestado, um equivalente possível hoje seria a idéia de Estado-nação, ou seja, uma instituição autônoma, que representa os interesses dos seus cidadãos e que é responsável por promover o bem geral. O que interessa ao refletir sobre estas palavras de Aristóteles é que para ele existe uma estreita interdependência entre os sujeitos que fazem parte da cidade. Esta aproximação ocorre, em especial, por meio da participação nos rumos da cidade, e que é responsável pela inauguração do espaço de interação político - a polis (Morrall, 1981). Ainda segundo Aristóteles, o surgimento da cidade é fruto de um crescimento, de algo que vai se desenvolvendo até atingir a forma madura. Assim, temos a família, depois o povoado e, por fim, a forma mais acabada de agrupamento que seria a cidade (Aristóteles, 1985).

\section{Uma segunda digressão: o ideal do nacional-desenvolvimentismo}

Juscelino Kubitscheck é considerado o criador de Brasília. Segundo Moreira (1995), a princípio a construção da capital não fazia parte do Plano de Metas de JK, a idéia surgiu após um comício no Estado do Goiás onde JK passa a incluir a construção da capital aos 30 pontos do seu plano de governo. Brasília representaria segundo Moreira, a meta-síntese do seu projeto "50 anos em 5".

O ideário do nacional-desenvolvimentismo tinha como pressuposto a realização de um crescimento que permitisse o surgimento de um mercado de consumo interno (Vesentini, 2001). Para tanto se deveria realizar uma política de substituição das importações. Por essa política o país priorizaria a importação de máquinas e implementos voltada para a industrialização do país (Fausto, 2001; Guido, 2002). Tal política procurou consolidar a industrialização brasileira ampliando a indústria de base e instalando indústrias pesadas (Caldeira et al.,1997; Aquino et al., 2000).

O slogan "50 anos em 5" tem como pressuposto a valorização do desenvolvimento econômico. Segundo Nunes, a matriz do Plano de Metas está nos discursos produzidos pela Comissão Econômica para a América Latina (Cepal) que por meio das análises de Prebisch ${ }^{2}$ 
propunha a necessária industrialização da América Latina como forma de romper sua dependência em relação às nações desenvolvidas (Nunes, 2004). Segundo Esteva, a idéia de desenvolvimento estava na pauta das nações do mundo inteiro desde a posse do presidente americano Donald Truman em 1945. Esse pressuposto articula-se ainda com a idéia de que o Brasil era uma nação atrasada e que devia se fortalecer economicamente no cenário mundial (Esteva, 2000).

A idéia de desenvolvimento também estava explícita não apenas no projeto de JK como também fazia parte do "Relatório do Plano Piloto". Segundo Lúcio Costa a capital deveria funcionar como uma fomentadora do desenvolvimento regional. E em médio prazo deveria alterar também os rumos desenvolvimentistas da nação (Costa, 1962). Ainda segundo Costa o ideal modernista tinha uma proposta de mudança social por meio da ação direta dos planos urbanísticos e arquitetônicos (Costa, 1962).

Naquela perspectiva Sousa (1983) afirmava que a construção de Brasília respondia à necessidade de construir um pólo intermediário entre o Sudeste e as regiões Norte e Centro-Oeste; outro objetivo seria o de servir de pólo integrador destas regiões e, conseqüentemente, do Brasil. No espectro político, Brasília simbolizava o progresso e a ideologia desenvolvimentista. Assim, podemos afirmar que Brasília era praticamente o símbolo de um projeto político o Plano de Metas de JK (Oliveira, 1997; Vesentini, 2001).

\section{Uma terceira digressão: os discursos sobre Brasília}

Segundo Nunes (1997), Brasília está encoberta por representações que são construídas sobre a cidade. Tais representações, segundo ele, não apenas são importantes para compreendermos Brasília como são marcas representativas da identidade da cidade. Esta afirmação nos leva a uma questão recorrente quando pensamos sobre Brasília: O que é Brasília? Qual a identidade da capital brasileira? E, finalmente, qual o significado de Brasília?

De acordo com Mariza Veloso Motta, pensar Brasília implica em compreender os movimentos que compõem as práticas modernistas. Ela destaca que um traço definidor da cidade está na "estetização da vida cotidiana" (Motta, 1997, p. 282). Por meio desta estetização se constrói uma distinção por subgrupos da classe média (Motta Santos, 1997). Nessa mesma perspectiva, Maria Angélica Madeira indica que o processo de adesão dos jovens em seus grupos ocorre dentro do universo da chamada cultura mundializada (Madeira, 1997). Assim, de acordo com as duas autoras, a cultura brasiliense apresenta um quadro muito próximo à das capitais mundializadas. Isto é perceptível por meio das práticas de sociabilidade produzida no espaço urbano da capital.

Falamos até aqui da perspectiva simbólica da cidade. Há ainda os dados sobre a realidade tangível da cidade, como a lógica da segregação entre ricos e pobres (Gouvêa, 1995; Oliveira, 1999; Tosta, 2000; Oliveira, 2000). Esta realidade, segundo Nunes (2004) é fortemente perceptível em Brasília. Analisando também nesta linha, Paviani (1996) vai afirmar que a urbanização de Brasília produziu dois modelos urbanos: uma periferia pobre e afastada do poder e sem acesso condizente aos equipamentos sociais e um centro representado pela área do Plano Piloto pertencente a uma elite econômica. Ainda nas palavras do autor (Paviani, 1996, p. 228):

O exemplo clássico de extirpar de áreas ditas "nobres" os favelados só poderá servir à manutenção do status quo, sem atingir a profundidade que se exige para transformar o pobre/desvalido ou "precarizado" em cidadão. As transformações, portanto, dependem de um grande esforço da sociedade como um todo...".

\section{Dois momentos de Brasília em Clarice Lispector}

Numa primeira leitura reconhecemos que o texto de Clarice Lispector (1999) parece realmente expor todo um conjunto de críticas objetivando construir um discurso anti-Brasília. Entretanto, gostaríamos de realizar uma reflexão mais minuciosa. Faremos uma leitura onde pretendemos denunciar a perspicácia da escritora no seu jogo com as palavras. Por meio de uma duplicidade nas construções das palavras, a autora amarra numa frase o duelo entre a paixão e o ódio, o desejo e a aversão, entre o sonho e a realidade. Visto apenas por recortes o conto "Brasília" daria margem tanto para engrandecer a cidade quanto para desprezála. Entretanto destaca (Lispector, 1999, p. 40-41):

Se eu dissesse que Brasília é bonita veriam imediatamente que gostei da cidade. Mas se digo que Brasília é a imagem de minha insônia vêem nisso uma acusação. Mas a minha insônia não é bonita nem feia, minha insônia sou eu, é vivida, é o meu espanto. É ponto e vírgula. Os dois arquitetos não pensaram em construir beleza, seria fácil: eles ergueram o espanto inexplicado. A criação não é uma compreensão, é um novo mistério.

Para evitar tal viés, procuramos extrair algumas unidades significativas que expressassem ambos os lados do discurso da escritora. 


\section{Primeiro momento: 1962, um ano de incertezas}

\author{
Criação da cidade
}

- Brasília é artificial. Tão artificial como devia ter sido o mundo quando foi criado.( p. 40).

- Quando o mundo foi criado, foi preciso criar um homem especialmente para aquele mundo. Nós somos deformados pela adaptação à liberdade de Deus. Não sabemos como seríamos se tivéssemos sido criados em primeiro lugar e depois o mundo deformado às nossas necessidades (p. 40).

- Sou atraída aqui pelo que me assusta em mim. Nunca vi nada igual no mundo. Mas reconheço esta cidade no mais fundo de meu sonho. O mais fundo de meu sonho é uma lucidez ( p. 42).

Clarice Lispector (1999) não tem nenhuma motivação para discutir (pelo menos neste texto) sobre a oportunidade ou não da mudança da capital e da criação de Brasília. Entretanto, antes de ser indiferente ela demonstra de forma sutil certo apreço e encanto pela criação realizada pelos dois arquitetos: “(...) reconheço esta cidade no mais fundo de meu sonho. O mais fundo de meu sonho é uma lucidez" (Lispector, 1999, p. 42).

\section{Ação política}

- Quando a noite veio percebi com horror que era inútil: onde eu estivesse seria vista. O que me apavora é: vista por quem? - Foi construída sem lugar para ratos. Toda uma parte nossa, a pior, exatamente a que tem horror de ratos, essa parte não tem lugar em Brasília ( p. 41).

- Mas os ratos, todos muito grandes, estão invadindo. Essa é uma manchete invisível nos jornais. - Aqui eu tenho medo. - A construção de Brasília: a de um Estado totalitário ( p. 41-42).

- Mas vejo ao longe urubus sobrevoando. O que estará morrendo, meu Deus? - Não chorei nenhuma vez em Brasília. Não tinha lugar. - É uma praia sem mar. - Em Brasília não há por onde entrar, nem há por onde sair ( p. 42).

De forma geral o que prevalece nas primeiras impressões sobre Brasília, segundo a autora, denota uma forte preocupação com o futuro próximo da cidade. Se relembrarmos o contexto político, podemos afirmar que a autora antevia um futuro de incertezas dominando o cenário da Administração Pública Federal. Para apresentar este cenário ela se utiliza da figura do rato. Aqui ele possui dois significados: a) de sujeito comum e b) de larápio.

$\mathrm{Na}$ primeira acepção ela afirma que Brasília "Foi construída sem lugar para ratos". O sujeito co- mum aqui é o povo. Povo também implica na idéia de multidão. Segundo Simmel (1973), é no meio da multidão da metrópole que se forma o anonimato. Isto faz com que a autora reclame: "Quando a noite veio percebi com horror que era inútil: onde eu estivesse seria vista." (Lispector, 1999, p. 41). Não havia povo. Qualquer um que precisasse se esconder seria facilmente localizado ou reconhecido. Havia, assim, um ar de vulnerabilidade.

$\mathrm{Na}$ segunda acepção Lispector afirma que se não tinha ratos (povo), "os ratos, todos muito grandes, estão invadindo" (Lispector, 1999, p. 41-42). Portanto, a cidade era objeto de cobiça por parte de empreiteiros de olho nas oportunidades e de políticos que tanto sonhavam com a tomada do poder sem a resistência popular: "Aqui eu tenho medo. A construção de Brasília: a de um Estado totalitário" (Lispector, 1999, p. 41-42). De acordo com Aquino et al. (2000) o governo de JK foi alvo de inúmeras tentativas de golpe. No entanto, embora houvesse uma forte resistência da oposição ao Governo de Juscelino Kubitschek, ele não teve dificuldades em aprovar a transferência da capital (Pantoja, 2004).

\section{O mundo das pessoas}

- Uma prisão ao ar livre. De qualquer modo não haveria para onde fugir. Pois quem foge iria provavelmente para Brasília. - Prenderam-me na liberdade. Mas liberdade é só o que se conquista ( p. 42).

- Se não for povoada, ou melhor, superpovoada, será tarde demais: não haverá lugar para pessoas. Elas se sentirão tacitamente expulsas ( p. 42).

Em Brasília, faltava aos olhos de Clarice Lispector, o povo. Assim ela expressa sua preocupação com a ausência do povo na Capital Federal: "Se não for povoada, ou melhor, superpovoada, será tarde demais..." (Lispector, 1999, p. 42). Na mesma linha de raciocínio Aquino et alii (2000), destacam tal distanciamento: A construção de Brasília representou nova realidade política para o Brasil. Longe da pressão direta das massas, habitada inicialmente por funcionários públicos, militares e parlamentares, a nova capital se afastava da população (Aquino et al 2000, p 542).

\section{O controle do Estado}

- Só Deus sabe o que acontecerá em Brasília. É que aqui o acaso é abrupto. - Brasília é mal-assombrada. É o perfil imóvel de uma coisa. - De minha insônia olho pela janela do hotel às três horas da madrugada. Brasília é a paisagem da insônia ( p. 43).

- Há alguma coisa aqui que me dá medo. Quando eu descobrir o que me assusta, saberei também o que amo aqui. O medo sempre me guiou para o que eu quero. E porque eu quero, temo ( p. 44). 
Tarde demais. Dois anos depois, em 1964, ocorrerá o Golpe Militar. Porém, em 1962 Lispector apenas poderia afirmar que "Só Deus sabe o que acontecerá em Brasília”" (Lispector, 1999, p. 43). Mas o que a autora ama ou teme? Como uma profissional das artes ela, muito provavelmente, ama a criação, porém teme pelo futuro da obra.

\section{Sociabilidade}

- Aqui é o lugar onde os meus crimes (não os piores, mas os que não entenderei em mim), onde os meus crimes gélidos têm espaço. Vou embora. Aqui meus crimes não seriam de amo (. p. 42).

- Se há algum crime que a humanidade ainda não cometeu, esse crime novo será aqui inaugurado. E tão pouco secreto, tão bem adequado ao planalto, que ninguém jamais saberá. - Aqui é o lugar onde o espaço mais se parece com o tempo. - Tenho certeza de que aqui é o meu lugar certo ( p. 43).

Por fim, numa última representação elaborada pela autora, toma como base o "efeito" ou as possibilidades ofertadas pelo meio ao indivíduo. Como as afirmações fazem parte de um conjunto, podemos afirmar que a autora demonstra como Brasília representa um ambiente adequado para os planos de tomada do poder: "Aqui é o lugar onde os meus crimes (...), onde os meus crimes gélidos têm espaço" (Lispector, 1999, p. 43). Como os objetivos dos representantes militares que sempre atentaram contra os princípios democráticos eram em favor das elites brasileiras, a autora complementa: "Vou embora. Aqui meus crimes não seriam de amor" (Lispector, 1999, p. 42).

\section{Segundo momento, 1974, encanto, medo e decepção.}

O segundo encontro da autora com Brasília demonstra um universo composto de medo, temor, de sigilo, de vigilância. Ao mesmo tempo Brasília ainda mantém um ar utópico. Ela é uma obra-prima da arquitetura. Como tantas outras obras originais ela possui a marca da autenticidade. Já dizia Benjamin (1994) "A esfera da autenticidade, como um todo, escapa à reprodutividade técnica ..." (Benjamin, 1994, p. 167). Podemos ter "várias" Brasílias, mas apenas no nome, não na arquitetura. Assim sua "aura" permanece, muito embora ela tenha sido ofuscada pelas brumas da repressão política.

\section{Criação da cidade}

- Brasília é uma cidade abstrata. E não há como concretizá-la. É uma cidade redonda e sem esquinas. Também não tem botequim para a gente tomar um cafezinho ( p. 44).

- Brasília não admite diminutivo. Brasília é uma piada estritamente perfeita e sem erros ( p. 44).

- Vou agora escrever uma coisa da maior importância: Brasília é o fracasso do mais espetacular sucesso. Brasília é uma estrela espatifada. Estou abismada. É linda e é nua ( p. 46).

- Quero esquecer Brasília mas ela não deixa. Que ferida seca. Ouro. Brasília é ouro. Jóia. Faiscante. Tem coisa sobre Brasília que eu sei mas não posso dizer, não deixam. Adivinhem ( p. 52).

Nesse momento as críticas são mais contundentes, porém, devemos ter o cuidado de lembrar o duplo contexto: a da obra de arte e a do regime de exceção. A autora se refere um êxito e a um fracasso. O êxito, o fracasso caminham juntos em suas palavras.

Assim se Brasília é "abstrata" como o são as obras de arte, não há como "concretizá-la" por não ter se tornado a cidade sonhada. Não tem espaço para o povo "sem esquinas". Se ao mesmo tempo ela "não admite diminutivo" também é "uma estrela espatifada". Uma frase, no entanto, é bem expressiva: "Brasília é o fracasso do mais espetacular sucesso". Aqui percebemos que tanto a cidade deu certo, "espetacular sucesso" quanto errado, "é o fracasso". A autora, no entanto, não esgota seus argumentos, ela nos convida sutilmente a buscar mais em suas palavras: "Brasília é ouro. Jóia. Faiscante. Tem coisa sobre Brasília que eu sei mas não posso dizer, não deixam. Adivinhem" (Lispector, 1999, p. 52).

\section{Ação Política}

- O clima é desafiador e chicoteia um pouco a gente. Mas falta magia em Brasília, falta macumba. Não quero que Brasília me rogue praga: pois pega. Rezo. Rezo muito. Ai que Deus bom. Tudo lá é às claras e quem quiser que se vire. Embora os ratos adorem a cidade. Qual será a comida deles? ah, já sei: eles comem carne humana (p. 47).

- Em Brasília não entra qualquer um, não. É preciso nobreza, muita sem-vergonhice e muita nobreza. Brasília não é. É apenas o retrato de si própria (p. 50).

- Brasília diz que quer mas não quer: negaceia. Brasília é um dente quebrado bem na frente. E é cúpula também. Tem um motivo principal. Qual é? segredo, muito segredo, sussuros, cochichos e chichos. Dizque-diz que não acaba mais (p. 51).

Para Lispector, Brasília foi tomada pelo jogo político das oligarquias brasileiras. Isto é possível, como já antevia na primeira parte da crônica em 1962, pela "falta de macumba". Podemos ler aqui a idéia de povo, já que a macumba sempre foi ligada à "coisas" do povo. 
No jogo da troca de favorecimentos, como tem sido historicamente no Brasil, a elite se locupleta sugando os recursos estatais. Segundo a autora, "Tudo lá é às claras e quem quiser que se vire". Reforçando esta linha de raciocínio ela afirma em seguida que os ratos adoram a cidade. Aqui podemos entender a figura dos ratos como uma representação da elite brasileira que administra o Estado em seu favor e em detrimento da população. Ela diz que em Brasília se "negaceia" um trocadilho que pode ser tanto lido como sinônimo de "negociata" quanto "negação da ceia", ou a negação das benesses sociais para o povo.

O projeto político da ditadura procurou segundo Chauí et al. (1985), estabelecer uma classe média com capacidade de consumo, para tanto o governo levou a cabo um programa de concentração da renda o que ampliou não apenas a desigualdade quanto tornou ainda mais crítica a situação dos pobres. Assim ela conclui: Qual será a comida deles? ah, já sei: eles comem carne humana" (Lispector, 1999, p. 47).

\section{O mundo das pessoas}

- No ano 2000 vai ter festa lá. Se eu estiver viva, quero participar da alegria. Brasília é uma alegria geral exagerada. Um pouco histérica, é verdade, mas não faz mal (p. 50).

- Em Brasília é sempre domingo. Mas agora vou falar bem baixinho. Assim: meu amor. Meu grande amor. Tenho dito? Você é que responde. Vou terminar com a palavra mais bonita do mundo. Assim bem devagarzinho: amor mas que saudade. A-m-o-r (p. 52).

- Em Brasília dá vontade de ser bonita. Tive vontade de me enfeitar. Brasília é arriscada e eu amo o risco. É uma aventura: me deixa face a face com o desconhecido. Vou dizer palavras. As palavras nada têm a ver com as sensações. Palavras são pedras duras e as sensações delicadíssimas, fugazes, extremas. Brasília humanizou-se. Só que não agüento essas ruas redondas, essa falta vital de esquinas (p. 58).

Se em 1962, Lispector reclamava da ausência do povo em Brasília, ou seja, se "não for super-povoada" então "será tarde demais", em 1974 ela aponta para o domínio do controle social, da cidade dominada pela ausência de pessoas. Esta ausência é perceptível na afirmação de que em Brasília é sempre domingo, ou seja, um dia em que as pessoas ficam em casa e que as ruas não possuem o movimento caótico dos dias de trabalho.

Outro elemento que conta para retirar as pessoas das ruas, segundo Lispector, é que Brasília foi feita sem "esquinas". Aqui podemos entender essa ausência em um sentido mais amplo de espaços de sociabilidades que funcionem como as velhas esquinas tão presentes nas cidades comuns, ou seja, de espaços perto de casa aonde se vai a pé encontrar os amigos. Depois do Golpe, a autora só antevê a presença do povo no ano 2000 - o que denotava uma possibilidade muito distante.

\section{O controle do Estado}

- Prefiro o entrelaçamento carioca. Fui delicadamente acarinhada em Brasília mas morri de medo de ler a minha palestra (p. 46).

- A moça me revistou toda no aeroporto. Eu perguntei: tenho cara de subversiva? Ela disse rindo: até que tem. Nunca me apalparam tanto, Virgem Maria, até que é pecado. Foi um tal de passar a mão em mim que nem sei como agüentei (p. 51).

- Brasília é o mistério classificado em arquivos de aço. Tudo lá se classifica. E eu? quem sou? como é que me classificaram? Deram-me um número? Sinto-me numerificada e toda apertada. Mal caibo dentro de mim. Eu sou um euzinho muito mixa. Mas com certa classe (p. 56).

- O que será de Brasília no ano, digamos, de 3000? Quanta ossada. Ninguém se lembra do futuro porque não pode ser. As autoridades não deixam. E eu, quem sou? obedeço de puro medo ao mínimo soldado que apareça na minha frente e me diga: considere-se prendida (p. 57).

Se Brasília possui um lado que seduz, certamente, o universo da criação e de construção de uma imagem de utopia, uma imagem de futuro; há um outro que não atrai a autora. Este é o lado do forte controle social exercido por um governo de exceção, um governo que se utiliza da investigação, da espionagem e de diversos outros aparatos para intimidar quaisquer atividades que contestem os valores oficiais. Aqui Brasília surge como um espaço da burocracia catalogando os indivíduos para exercer domínio sobre eles. Nas palavras da autora ela afirma que "Brasília é o mistério classificado em arquivos de aço. Tudo lá se classifica. E eu? quem sou? como é que me classificaram? Deramme um número? Sinto-me numerificada e toda apertada" (Lispector, 1999, p. 56).

Tal cenário de controle social cria uma situação de fragilidade e de insegurança do indivíduo perante os poderes públicos. Assim se expressa a autora: "obedeço de puro medo ao mínimo soldado que apareça na minha frente e me diga: considere-se prendida" (Lispector, 1999, p.57). Tal panorama está presente também noutras palavras: "Fui delicadamente acarinhada em Brasília mas morri de medo de ler a minha palestra" (Lispector, 1999, p. 46).

\section{Sociabilidade}

- Adoro Brasília. É contraditório? Mas o que é que não é contraditório? Só se anda de carro pelas ruas despovoadas. Quando eu tinha carro e dirigia, vivia me perdendo (p. 47). 
- Brasília é magra. É toda elegante. Usa peruca e cílios postiços. É pergaminho dentro de Pirâmide. Não envelhece. É coca-cola, meu Deus, e vai me sobreviver. Que pena. Para a coca-cola, é claro. Socorro! Socorro! Help me! Sabe qual é a resposta de Brasília ao meu pedido de socorro? É oficial: aceita um cafezinho? E eu? fico sem socorro? Me trate bem, ouviu? (p. 52).

- Eu não sou nada. Sou um domingo frustrado. Ou estou sendo ingrata? Muito me foi dado, muito me foi tirado. Quem ganha? Não sou eu não. É alguém hiperbólico (p. 55).

Finalmente podemos afirmar que, segundo Clarice Lispector, Brasília não conseguiu concretizar o seu projeto social. Mas qual era o "projeto" brasiliense? Brasília era parte, ou melhor, o coroamento do projeto desenvolvimentista de Juscelino Kubitschek. Assim o descreve Bastos (1986, p. 18-19):

O momento da criação de Brasília é um instante único na História do País, desses que alteram silenciosamente o destino de um povo.

Foi num clima de depressão psicológica e crise econômica - depois da mediocridade de Governo Dutra e do retorno e suicídio de Vargas - que Juscelino ergueu seus estandartes de otimismo e a promessa de que faria o país progredir cinqüenta anos em cinco, de seu mandato. "50 anos em 5" era o slogan de sua campanha. Eleito, ele orientou seu governo em função de metas ambiciosas, verdadeiramente mirabolantes aos olhos de uma população envergonhada por sua impotência.

Se a cidade prometia edificar uma sociedade moderna, ela serviu de suporte para o estabelecimento de uma sociedade controlada com base em uma máquina burocrática e centralizadora. Para garantir tal controle os representantes do Estado de exceção mantiveram o povo distante e venderam uma máscara ou imagem de modernização da Nação - o chamado "Brasil Potência” (Oliveira, 1998). Por ocasião dos 25 anos da cidade Gullar (1986, p. 19) escrevia:

O tempo passou. Brasília completa 25 anos. Como parte da realidade brasileira e fruto dela, não poderia ter crescido e se formado livre dos problemas e das injunções dessa realidade. Pode-se dizer mesmo que ela encarna hoje a síntese desses problemas, refletindo as poucas virtudes e os muitos defeitos de nossa sociedade desigual.

Para Clarice Lispector, podemos afirmar, o projeto de modernização implementado pelo governo militar tornou a cidade "magra", "elegante", que "usa peruca" e tem “cílios postiços”. Estas são referências para os indivíduos pertencentes à elite nacional. Porém o preço, segundo a autora, que a dependência ao capital externo: "É coca-cola, meu Deus, e vai me sobreviver. Que pena. Para a coca-cola, é claro. Socorro! Socorro! Help me! Sabe qual é a resposta de Brasília ao meu pedido de socorro? É oficial: aceita um cafezinho?" (Lispector, 1999, p. 52).

\section{Conclusão: a cidade e seus contrastes}

Relembrando nossa primeira digressão, contrastando Brasília com a idéia da cidade grega - tomando apenas a linha de raciocínio geradora de seu surgimento -, reconhecemos que Brasília não foi fruto de uma aspiração coletiva, mas de uma idealização particular. Se a idéia possuía matrizes bem mais antigas (que remontam ao Império na figura de José Bonifácio) ela nunca se enraizou nos meios populares. A cidade grega, segundo Aristóteles, representava o bem maior uma vez que ela produzia o espaço para o crescimento do cidadão - um crescimento político e filosófico. Brasília surge também como um projeto de crescimento, porém com um viés técnico e em benefício de um reduzido segmento em detrimento dos princípios da democracia e do cidadão. Segundo Caldeira et al. (1997, p. 295), assim se argumentava em defesa da nova capital:

O projeto tinha justificativas objetivas: a construção da nova capital numa região pouco povoada levaria o desenvolvimento ao interior; as novas estradas ampliariam as fronteiras agrícolas; a própria construção da cidade iria gerar oportunidades de emprego. Tinha a vantagem também de desviar a atenção de problemas complexos, como a reforma agrária.

A despeito daqueles que professavam a idéia de desenvolvimento como uma forma de produzir melhorias, a elite política não tinha interesse em distribuir os bens - mesmo para os mais identificados com um discurso próximo aos anseios do povo como Getúlio Vargas. Conforme salientou Caldeira (1997), a construção de Brasília servia também como um forte elemento para atenuar ou desviar as tensões sociais vividas pelo Brasil.

Assim, com relação à segunda premissa, Brasília nasce como uma "meta-síntese" de um projeto de desenvolvimento. Os rumos, no entanto, foram inteiramente distintos do discurso produzido. Se os objetivos (pelo menos o que foi publicizado) eram industrializar para distribuir riquezas, tal sonho (por não ser, de fato, um dos propósitos da elite brasileira), nos governantes que se seguiram acabou por se concretizar em políticas ainda mais concentradoras.

Finalmente, o ideal da distribuição de bens foi liquidado com o esgotamento de alguns modelos econômicos e filosóficos, além do contexto das tensões 
políticas. Entre tais modelos podemos apontar o chamado "fim do fordismo". Segundo Harvey (1989), o fordismo se expandiu fortemente após a Segunda Grande Guerra tornando-se não apenas um sistema de produção, mas praticamente um modo de vida. Entretanto, a partir do final dos anos 1960 e início dos anos 1970 o Estado se vê incapaz de financiar e assegurar a entrada de diversos grupos que ainda não tiveram acesso "às tão louvadas alegrias do consumo de massa" (Harvey, 189, p. 132). Os modelos que se seguem terão como prioridade a redução do custo, porém propõe modelos flexíveis que implicavam tanto no corte de pessoas quanto na redefinição dos direitos sociais.

No Brasil, o projeto de desenvolvimento técnico atingirá seu ápice no período do regime militar. Porém, como já salientaram Chaú et al. (1986), primordialmente tratou de produzir uma classe média consumidora e, para tanto desencadeou programa de concentração de renda. Tal modelo criou o que muitos analistas mais tarde identificarão como "modernização conservadora", ou seja, realização de um desenvolvimento econômico que pouco ou nada modificou satisfatoriamente as condições sociais dos brasileiros em geral. Brasília, também representará bem o cenário de apartação entre pobres e ricos. Este processo se dará por meio da segregação de caráter socioeconômico. Nas palavras de Nunes (2004, p. 167):

... o que se verifica é que o processo de consolidação de Brasília - ou Distrito Federal - vem se dando por um aumento no número de cidades satélites que caracteriza uma rede urbana sub-regional com claros indícios de uma futura metrópole se as conturbações potenciais se concretizarem. Pode-se avançar ainda a hipótese de que esta futura metrópole tenderia a apresentar características típicas das grandes cidades brasileiras: segregação espacial, periferização da população, poluição, elevados índices de violência. A disponibilidade de terras aqui existente termina por funcionar como fator de atração suficiente para justificar o translado de parcela importante do número de famílias de migrantes das áreas deprimidas que a cerca.

As possibilidades indicadas por Nunes já estão bastante evidenciadas se acompanharmos mais pon- tualmente as condições das cidades-satélites. Diante desse cenário poderíamos indagar como foi possível criar tal modelo de ordenamento social diante de uma sociedade que vivia às turras com os representantes do poder? Lispector diria que "Brasília é Lei Física", ou seja, a força. A lógica da força esteve bem expressa no lema "Brasil, ame-o ou deixe-o". Não há discussão sobre outras possibilidades. Porém, a força não é nem foi uma primazia brasiliense. A matriz positivista brasileira já havia importado o lema "Ordem e progresso", ou seja, para haver progresso é preciso que se elimine a desordem. Afinal os que contestavam não eram sempre vistos como agentes da desordem? Lispector (1999, p. 61) continua "Brasília é Marcha Nupcial. O noivo é um nordestino que come o bolo inteiro porque está com fome há várias gerações. A noiva é uma velha senhora viúva, rica e rabugenta".

A realidade brasiliense não é diversa se comparado ao restante do Brasil. As disparidades dos indicadores econômicos denunciam que a "velha senhora viúva, rica e rabugenta" demonstrou, nos últimos anos que possui uma forte tradição: a da concentração das riquezas. Ainda que a elite nacional tenha aceitado a realização do processo de redemocratização, ela o fez sem que isso implicasse uma redistribuição dos bens. Uma observação da região do Distrito Federal nos aponta para a existência de duas Brasílias: uma rica e outra pobre. Nesse aspecto, Brasília é um retrato fiel do Brasil. Em vários momentos Lispector chamou a atenção para o fato de que Brasília não tinha povo, não tinha "macumba" e ela que deveria ser logo superpovoada. Lispector demonstrava seu temor com a implantação de um regime totalitário e de seus desdobramentos. Os traços mundializados e, supostamente, multiculturais são suficientes para imaginarmos, talvez a cidade em si, mas não para generalizarmos sua dinâmica urbana como se fosse fruto de uma construção dos brasileiros, de uma brasilidade.

Brasília é única, assim, está demonstrado pela preocupação de agências nacionais e internacionais com sua preservação. Porém ela é partida, segregada pelas barreiras que separam as cidades-satélites do Plano Piloto, pelas barreiras que separam Brasília do restante da população do Brasil que ainda possui dificuldade de sentir e perceber a cidade como parte de sua vida.

\section{Referências}

ANDRADE, C. D. de. Versiprosa. Rio de Janeiro: José Olympio Editora, 1967.

Favelário Nacional - Confronto In: ANDRA-

DE, C. D. de. Corpo. 11. ed. Rio de Janeiro: Editora

Record, 1984, p. 109-124.

AQUINO, R. S. L. et alii. Sociedade brasileira: uma história

através dos movimentos sociais: da crise do escravismo ao apogeu do neoliberalismo. Rio de Janeiro: Editora Record, 2000.

ARISTÓteles. Política. Tradução de Mário da Gama Kury. Brasília: Editora da UnB, 1985.

BASTOS, O. Lúcio Costa In: MONTEIRO, Salvador; 
KAZ, Leonel. Brasília. Rio de Janeiro/Brasília: Edições Alumbramento, 1986, p.3-36.

BENJAMIN, W. Magia e técnica, arte e política: ensaios sobre a literatura e história da cultura (Obras escolhidas). v. 1. Tradução de Sergio Paulo Rouanet. São Paulo: Editora Brasiliense, 1994.

BURSZYN, M.(Org.). No meio da rua: nômades, excluídos e viradouros. Rio de Janeiro: Editora Garamond, 1999.

BURSZYN, M.; ARAÚJO, C. H. Da utopia à exclusão: vivendo nas ruas de Brasília. Rio de Janeiro/Brasília: Editora Garamond/Codeplan, 1997.

CALDEIRA, J. et al Viagem pela história do Brasil. São Paulo: Companhia das Letras, 1997.

CAMPEDELLI, S. Y.; ABDALA Jr., B. Clarice Lispector. São Paulo: Abril Educação, 1981.

CHAUÍ, M.; CÂNDIDO, A.; ABRAMO, L.; et al.. Política Cultural. 2. ed. São Paulo: Fundação Wilson Pinheiro/Editora Mercado Aberto, 1985.

COSTA, L Sobre arquitetura. Porto Alegre-RS: Editora da UFGRS,1996.

DEMO, P. O charme da exclusão social. Campinas-SP: Editora Autores Associados, 1998.

DUARTE DA SILVA, L. S. A construção de Brasília: modernidade e periferia. Goiânia (GO): Ed. da UFG, 1997.

DREIFUSS, R A. 1964: a conquista do Estado: ação política, poder e golpe de classe. Petrópolis (RJ): Editora Vozes, 1981.

ESTEVA, G. Desenvolvimento In: SACHS, W. Dicionário do desenvolvimento: guia para o conhecimento como poder. Tradução de Vera Lúcia M. Joscelyne, Susana de Gyalokay e Jaime A. Clasen. Petrópolis (RJ): Editora Vozes, 2000, p. 59-83.

FAUSTO, B. História concisa do Brasil. São Paulo: Editora da USP/Imprensa Oficial do Estado, 2001.

GUIDO, C. Celso Furtado. Rio de Janeiro: Fundação Getúlio Vargas. Disponível em: http://www.cpdoc.fgv. br/dhbb/. Acesso em: 15 de abr. de 2003.

GULLAR, F. Oscar Niemeyer In: MONTEIRO, S.; KAZ, L. Brasília. Edições Alumbramento: Rio de Janeiro/ Brasília, 1986, p. 17-24.

GORENDER, J. Combate nas trevas: esquerda brasileira: das ilusões perdidas à luta armada. São Paulo: Editora Ática, 1987.

GOUVEIA, L. A. de C. Brasília: a capital da segregação e do controle social: uma avaliação da ação governamental na área de habitação. São Paulo: Editora Annablume, 1995.

HARVEY, D. A condição pós-moderna: uma pesquisa sobre as origens da mudança cultural. Tradução: Adail Ubirajara Sobral; Maria Stela Gonçalves. São Paulo: Edições Loyola, 1989.

LISPETOR, C. Para não esquecer: crônicas. Rio de Janeiro: Editora Rocco, 1999.

LOPES, L. C. Brasília: o enigma da esfinge - a construção e os bastidores do poder. Porto Alegre-RS/São LeopoldoRS: Editora Unisinos/Editora da Universidade, 1996.

MADEIRA, M. A. Formas de sociabilidade e a cultura da festa na juventude brasiliense dos anos 1990 In: NUNES, B. F. (Org.) Brasília: a construção do cotidiano. Brasília: Editora Paralelo 15, 1997, p. 253-270.

MIRANDA, N.; TIBÚRCIO, C. Dos filhos deste solo: mortos e desaparecidos políticos durante a ditadura mi- litar: a responsabilidade do Estado. São Paulo: Editora Perseu Abramo/Boitempo Editorial, 1999.

MOREIRA, R. S. C. Brasília, uma abordagem histórica e cultural. KELLOGG NATIONAL FELLOWSHIP PROGRAM - INTERNATIONAL SEMINAR. New York, 1995.

MORRALL, J. B. Aristóteles. Tradução de Sérgio Duarte. Brasília: Editora da UnB, 1981.

MOTTA SANTOS, M. V. O patrimônio modernista e a diversidade cultural. In: NUNES, B. F. (Org.). Brasília: A construção do cotidiano. Brasília: Editora Paralelo 15, 1997, p. 271-285.

NUNES, B. F. (Org.). Brasília: A construção do cotidiano. Brasília: Editora Paralelo 15, 1997.

NUNES, B. F. Brasília: fragmentos para a construção de um discurso sociológico sobre um espaço pensado. In: NUNES, B. F. (Org.). Brasília: A construção do cotidiano. Brasília: Editora Paralelo 15, 1997, p. 13-35. Brasília: a fantasia corporificada. Brasília: Editora Paralelo 15, 2004.

OLIVEIRA, D. D. de. Brasília: as possibilidades de construção de uma identidade de cidade-mundo. In: VIII CONGRESSO DA SOCIEDADE BRASILEIRA DE SOCIOLOGIA. Brasília, 1997.

Política cultural: um panorama sobre as relações entre o Estado e a cultura no Distrito Federal nas décadas de 70 e 80 In: Pós - Revista Brasiliense de PósGraduação em Ciências Sociais. Instituto de Ciências Sociais. Universidade de Brasília: Brasília, ano 2, n. 1. p. 89101, out. de 1998.

Migração e trajetórias: a saga de João de Santo Cristo In: OLIVEIRA et al. (Orgs.). 50 anos depois: relações raciais e grupos socialmente segregados. Brasília: MNDH, 1999, p. 203-219.

Migração, redes e projetos: os moradores de rua em Brasília In: BURSZYN, M. (Org.). 1999. No meio da rua: nômades, excluídos e viradouros. Rio de Janeiro: Editora Garamond, 2000, p. 172-191.

OLIVEIRA, M. de. O mito na trajetória da nação. Brasília: Paralelo 15 Editores, 2005.

PANTOJA, S. Juscelino Kubitschek. Rio de Janeiro: Fundação Getúlio Vargas. Disponível em: http://www. cpdoc.fgv.br/comum/htm/. Acesso em: 17 de jun. de 2004.

PAVIANI, A. A realidade da metrópole: mudança ou transformação na cidade? In: PAVIANI, A. (Org.). Brasília: moradia e exclusão. Brasília: Editora da UnB, 1996, p. 213-229.

SIMMEL, G. A Metrópole e a Vida Mental. In: VELHO, G. O Fenômeno Urbano. Tradução de Sérgio Marques dos Reis. 2. ed. Rio de Janeiro: Editora Zahar, 1973, p. 11-25.

SOUSA, N. H. B. de Construtores de Brasília: estudo de operários e sua participação política. Petrópolis-RJ: Editora Vozes, 1983.

TOSTA, T. L. D. Memória das ruas, memórias da exclusão In: BURSZYN, M. (org.). No meio da rua: nômades, excluídos e viradouros. Rio de Janeiro: Editora Garamond, 1999, p. 201-229.

VESENTINI, J. W. A capital da geopolítica. São Paulo: Editora Ática, 2001. 


\title{
The ways of the brasiliense utopia: reflections about how the federal capital is illustrated in Clarice Lispector's short story "Brasília"
}

\begin{abstract}
This paper analyzes Clarice Lispector's short story Brasília, written in the politically tense year of 1962 and at the apex of the "economical miracle". Published after her death, the story is emblematic as it traces society's expectations regarding the future of the capital. In this analysis the text was decomposed and confronted with sociological and historical literature to understand the story's underlining discourse. Furthermore, we come to the author's assumption that the absence of masses made the military coup d'etat "easier" as there would be no reaction without the populace.
\end{abstract}

Key-words: Brasília; city; Clarice Lispector.

Data de recebimento do artigo: 25 de agosto de 2007

Data de aprovação do artigo: 10 de dezembro de 2007 